\title{
Paul-Emmanuel Stradda, Dieu, matrice de la métaphysique
}

Revue Metaphysica theoria - Tome 5

Paris, L'Harmattan, coll. « Ouverture philosophique », 2012, 282 p.

Illustrations.

\section{Mustapha Naïmi}

\section{(2) OpenEdition}

Journals

Édition électronique

URL : http://journals.openedition.org/assr/26574

DOI : $10.4000 /$ assr.26574

ISSN : 1777-5825

Éditeur

Éditions de l'EHESS

\section{Édition imprimée}

Date de publication : 31 décembre 2014

Pagination : 297

ISBN : 978-2-7132-2467-6

ISSN : 0335-5985

Référence électronique

Mustapha Naïmi, « Paul-Emmanuel Stradda, Dieu, matrice de la métaphysique », Archives de sciences sociales des religions [En ligne], 168 | 2014, mis en ligne le 21 mai 2015, consulté le 22 septembre 2020. URL : http://journals.openedition.org/assr/26574 ; DOI : https://doi.org/10.4000/assr.26574 


\section{Paul-Emmanuel Stradda, Dieu, matrice de la métaphysique}

Revue Metaphysica theoria - Tome 5

Paris, L'Harmattan, coll. « Ouverture philosophique », 2012, 282 p.

Illustrations.

\section{Mustapha Naïmi}

\section{RÉFÉRENCE}

Paul-Emmanuel Stradda, Dieu, matrice de la métaphysique

Revue Metaphysica theoria - Tome 5

Paris, L'Harmattan, coll. « Ouverture philosophique », 2012, 282 p.

Illustrations. 
Ce volume V de Metaphysica theoria est la première dans la question philosophique de l'existence de Dieu. Il se présente comme une sorte de manuel destiné aux étudiants. Une suite de définitions élémentaires se succède depuis les principes de la métaphysique à la nécessité éthique et axiologique de l'homme en passant par la métaphysique de la relation, la théorie fondamentale de l'être et de l'unité, la nécessité spirituelle et religieuse de Dieu comme matrice de la métaphysique. La vérité absolue n'est pas un concept, elle touche au réel. Elle porte sur la relation au monde, sur la relation ontologique et hétérogène qui exprime les rapports d'être et d'existence, d'être et de causalité. Autrement dit, la causalité relationnelle est une ontologie au cœur de la positivité du réel, au cœur de la réalité de ce monde, parce qu'elle est une ontologie résolument relation. Dans cette logique purement métaphysique, nous sommes comme des êtres relationnels dans un univers relationnel. On peut voir en l'univers une manifestation significative de l'action créatrice de Dieu. Ainsi peut-on dire que « l'efficace des causes naturelles ne relève pas directement de la nécessité ", car tout dépend de la volonté divine, du mystère de la providence de la création, pense l'auteur. Pour finir, on peut conclure en soutenant que s'il y a une certaine relation entre la cause et l'effet, Dieu a voulu seulement que cela se présentât ainsi à nous.

2 Sur le plan spirituel, et dans une vision plus religieuse et paulinienne, la forme de l'univers se réfère à un but, à un ordonnateur, un créateur, un Dieu personnel. La cosmologie métaphysique emprunte des faits à la cosmologie scientifique, la première ne prétend pas se substituer à la seconde, montre à la raison réfléchissante que le message de la religion se trouve relié et amplifié par le passage tiré des éléments de l'univers.

a deuxième partie traite d'une approche philosophique de la notion de Dieu. Une phrase célèbre de Pascal oppose le « Dieu d'Abraham, d'Isaac et de Jacob » au Dieu des "philosophes et des savants", c'est-à-dire au Dieu de la raison. L'exigence philosophique étant une exigence d'intelligibilité n'empêche pas que le Dieu des prophètes ait le même que celui des philosophes. Il est plus fascinant d'examiner certaines questions à la lumière de l'intelligence et de la connaissance. Il convient de s'arrêter à la formulation de la question : Dieu existe-t-il ? La condition de l'énonciation de cette question se rencontre en revêtant un statut purement académique dans l'épistémè médiévale. C'est seulement au XIX ${ }^{\mathrm{e}}$ siècle que l'athéisme devient pensable laissant dans l'ombre le problème de la détermination de la divinité. Ludwig Feuerbach est le premier théoricien qui inaugure une forme élaborée de l'athéisme. Son argument essentiel porte sur le caractère déshumanisant de l'idée de Dieu. Sa philosophie ne se 
déploie pas au niveau ontologique, mais au niveau de la représentation de la divinité et de ses effets sur l'être humain : il s'agit alors de se demander à quelles conditions l'idée de Dieu demeure pensable ou, plus précisément, à mesurer le degré d'aliénation auquel cette idée soumet le sujet croyant. Marx, Nietzsche, puis Freud s'inscrivent dans cet espace de questionnement, contribuant à faire de la mort de Dieu la marque même de la modernité.

4 Néanmoins, il est intéressant de s'attarder sur la critique de Heidegger de l'ontothéologie, car il cherche à nouer avec la tradition philosophique qui réside dans la vigueur de ce qui a été pensé (Hegel). Il concrétise son dialogue avec l'ensemble de la tradition métaphysique en proposant une interprétation de la logique de Hegel. Dans le système hégélien, l'être se manifeste comme la Pensée, ce qui signifie qu'il faut nouer l'ontologique au théologique dans la mesure où le propos de la pensée ne peut être pensé à fond, qui lui rend raison, qui lui demande raison. La crise des fondements métaphysiques implique inévitablement une crise du discours théologique.

Considérant l'interaction profonde de la raison métaphysique et de la raison théologique, la crise des fondements métaphysiques implique inévitablement une crise du discours théologique. Il faut le reconnaître, cette crise se rapporte au même problème de la relation entre la métaphysique et le problème de Dieu. Il est évident qu'aujourd'hui la métaphysique parait à beaucoup d'égards démodée et même archaïque, réduite au statut d'un vieil héritage qui ne se maintiendrait que par une sorte d'inertie, en parasite de la science positive, ou, dans le cadre des études historiques, comme un chapitre de l'histoire de la culture. Elle est devenue, selon cette opinion, un corps étranger dans une culture dont les déterminants profonds relèvent d'autres dimensions de la vie de l'esprit. Sans aller nécessairement jusque là, il faut reconnaître à tout le moins que la métaphysique, à l'heure actuelle, est une dimension de la culture qui ne fait plus système avec les autres. Peut-être parce qu'elle se présente à nous sous la forme d'une extrême abstraction. Peut-être aussi l'idée d'une unité systématique de la culture doit-elle être abandonnée. D'autre part, affirmer un attachement à la métaphysique n'est rien d'autre que d'affirmer un attachement au droit de l'Absolu en philosophie, et donc aussi, comme l'indique sans ambiguïté le titre d'un ouvrage de Claude Bruaire, un attachement au « Droit de Dieu », car, in fine, il est trop évident que la métaphysique concerne le "problème" de Dieu. Il peut être dangereux pour la pensée et pour les hommes d'oublier ce point ultime de la pensée métaphysique. Si en effet, Heidegger a dénoncé, à juste titre, l'oubli de l'Être dans la pensée contemporaine, et, si, à juste titre encore, il a tenté de relancer cette question fondamentale, cette "question qui questionne la question", il a voulu opérer cette restauration dans l'oubli de Dieu et c'est pourquoi, comme le disait Ricœur, il n'est sorti de l'effort heideggérien qu'une sorte de "structuralisme métaphysique ", avec comme conséquence, une perte importante de dimension éthique. Cela dit, si l'on peut bien philosopher sans Dieu, cela n'implique pas que Dieu soit en dehors de la philosophie.

6 Ce qu'il est convenu d'appeler «culture religieuse " se retrouve dans un lamentable état de sous-développement. Une masse d'incultes opine benoîtement devant l'iconographie devenue incompréhensible de nos musées. Les médias ne retiennent de la foi et de son histoire que l'accessoire futile ou croustillant. Les symboles chrétiens ou la musique religieuse trouvent une utilisation commerciale en accompagnant les publicités parfois les plus scabreuses. Une inquiétante dichotomie nous habite. Une étrange schizophrénie nous ronge portant toutes les marques d'une psychose. Le 
refoulement est la mise en place de mécanismes de défense. Nous refoulons Dieu. Nous dressons nos défenses contre lui. Pire, Dieu devient notre ennemi, nous le combattons comme des « fils de la rébellion ». 